\title{
A REVIEW OF INDIAN GOVERNMENT INCLUSIVE INITIATIVES: POVERTY ON THE DECLINE
}

\author{
Dr. Sheetal Mundra \\ Assistant Professor, Institute of Management, JK Lakshmipat University, Jaipur \\ sheetalmundra5@gmail.com
}

Article History: Received on 02nd February Revised on 30th April, Published on 20th July 2019

\begin{abstract}
Purpose of the study: The ineffectiveness of the Indian development planning model reflected in India's largest share in the count of poor people for the year 2016. This paper depicts the current poverty situation and the importance of poverty reduction in India. It also explores the socioeconomic determinants affecting poverty across different states of India and the possible reasons of the recent decline in the poverty ratio in India during the Modi reform era (2015-2018).
\end{abstract}

Methodology: The study is based on secondary data. The data of 28 Indian states for the year 2009-10 and 2011-12 have been considered on key inclusive socioeconomic indicators, namely, Human Development Index (HDI), Work Participation Rate, Gini-coefficient, Gross State Domestic Product, Mahatma Gandhi National Rural Employment Guarantee Act expenditure, and Poverty Head Count Ratio. The variation in the poverty headcount ratio, having the combined effect of these indicators, has been measured through the multiple regression model and presented with the help of SPSS.

Main Findings: The paper concludes that HDI is the most significant determinant in both years (2009-10 and 2011-12) across different states of India. It underlines the fact that major inclusive initiatives during the Modi reform era have been coincidentally directed towards the improvement of health and education and the generation of income, resulting in poverty reduction. Thus, right initiatives require the right direction for their effectiveness.

Applications of this study: This study will help in highlighting the key inclusive initiatives of performance and in supporting these initiatives to reduce poverty in India. India can be considered as a model for many developing countries to follow such inclusive initiatives, identify the significant determinant of poverty, and get rid of it.

Novelty/Originality of this study: This paper sheds light on key determinants of poverty in the Indian context. The paper examines the government inclusive initiatives in the context of identifying the determinants that help in supporting the right initiatives towards the right direction, resulting in the reduction of poverty in India.

Keywords: Poverty, Poverty Headcount Ratio, Human Development Index, Inclusive Initiative

\section{INTRODUCTION}

India adopted the five year plan model as a tool for planned economic development since 1951 and continued until 2017. As a developing country, poverty eradication was one of the important objectives of this planned development model. The adoption of poverty alleviation strategies in the five year development model have resulted in continuous reduction in the ratio of poverty across India. Various employment and income generation schemes were implemented and different methodologies to estimate poor population were adopted. The economic philosophy behind this initiative was to provide preferential treatment to uplift poor people to enable them to participate and contribute in economic development (Raj Krishna, 1984).

Poverty is narrowly defined as physical deprivation from the essentials of wellbeing, particularly food, but also housing, clothing, and other assets (Narayan et al., 2000). It is also referred as the state of deprivation with respect to social inferiority, vulnerability, seclusion, physical weakness, subjection, and humiliation (Ogwumike and Odusola, 2001). Poverty examines the relative position of an individual on some absolute standards and distribution of individuals in terms of their departure from these standards in the society (Shrinivasan, 2013). It is a multidimensional phenomena (Narayan et al., 2000) marked as denial of capability from economic opportunities, public liberty, communal amenities, transparent transactions, and positive safety (Sen, 1999).

The poverty rate and head count ratio are the most common standards of measuring poverty. In 1979, a task force defined poverty line based on food expenditure worth 2,400 calories in rural area and 2100 calories in urban areas. In 2011, the Suresh Tendulkar Committee quantified the poverty line based on an individual expenditure worth Rs. 27.2 and Rs. 33.3 in a day on basic substances of living in rural and urban areas, respectively. This had been criticized for setting the low poverty line (Choudhury, 2015). The Rangarajan committee defined a new poverty line as one's spending on less than 
Rs. 32 and Rs. 47 in a day in rural and urban areas, respectively, resulting $29.5 \%$ poverty headcount ratio, which is $35 \%$ increase on $21.9 \%$, according to the estimation of the Tendulkar committee.

The World Bank (2008) projected that there was a decline of poverty ratio in India from 60\% in 1981 to $41.6 \%$ in 2005 on the basis of international poverty line defined as one's purchasing power parity below US $\$ 1.90$ per day. According to Economic Survey 2014-15, the total number of poor went down from 407.1 million (37.2\%) to 269.3 million (21.9\%) between 2004-05 and 2011-12, on the basis of monthly per capita expenditure (MPCE), at a rate of 2.2\% decline. The poverty head count ratio declined from 55\% in 2005-06 to $28 \%$ in 2015-16, with a fall of 271 million people in absolute terms on multidimensional poverty. Still, India's share of poor people in the world was the largest, about $1 / 3$ rd of the total world poor count in 2016 compared to 1/5th of the contribution 30 years ago. A study by the Oxford Poverty and Human Development found that poverty prevailed across Indian states but more than half of the Multi-dimension Poverty Index (MPI) poor people (196 million) were concentrated in four Indian states, namely, Bihar, Jharkhand, Madhya Pradesh, and Uttar Pradesh, in the year 2015-16 (UNDP, 2018). Thus, ineffectiveness of the development planning model highlighted the need of bridging the gap between the bottom of pyramid and the ideal strategies of planned development.

The Multi-dimension Poverty Index (MPI) comprised ten indicators under three significant dimensions: health, education, and standard of living. It measures not only the prevalence of poverty, but its intensity also. A person getting deprived scoring in three indicators out of 10 is classified as multidimensional poor. Still, there is no standardized poverty measurement criteria available in India, becomes a key concern for policy analysts and academic researchers to review the various methodologies for poverty measurement. Sen (1976) discussed two problems for the measurement of poverty, firstly to define poverty line and secondly to design an index to measure it.

Poverty reduction is the route to generate income and bring economic stability (Nalunkuuma, 2006). Adam Smith (1776) society cannot be happy with its large portion of poor and miserable people. Poverty entraps the poor in a vicious circle (Sachs, 2005; Sheperd, 2007). Poverty has multidimensional impact on the ecosystem. Sustainability and environmental deterioration are closely linked with poverty status. Poor are not able to use natural resources in a sustainable manner, thus poverty leads to environmental deterioration (Duraippah, 1996). Mr. Narendra Modi emphasized that poverty needs to be tackled to bring peace and development across the world on 25 September 2015 at the United Nations Sustainable Development Goals (UN SDG) Summit.

Poverty is one of the important development agendas of humanity and its reduction is the key to a good deal of malaise, humanity has been facing. The importance of poverty reduction can be understood through 17 post-2015 Sustainable Development Goals (SDGs), announced in 2015 at the UN summit, wherein 189 countries had pledged to end poverty in its various forms to bring about substantial changes in the life of fellow men, women, and children. The UN high-level panel published a report on 'A New Global Partnership: Eradicate Poverty and Transform Economies through Sustainable Development' in 2013 and briefed the post-2015 universal agenda for ending extreme poverty by 2030 (UN, 2013). The high level political forum adopted the theme 'Eradicating poverty and promoting prosperity in a changing world' in 2017 and included SDG 1 as one of the focus of SDGs. Poverty is the most critical concern affecting presentday World (Bruton et al., 2013). Thus, poverty eradication is an indispensable requirement for sustainable development.

There are two interconnected vicious circles, one is of affluence and the other is of poverty. The unequal distribution of income and the unequal distribution of assets are causing these vicious circles and it is necessary to correct them. Unless and until the corrective measures are taken, the problem of poverty eradication cannot be solved. Therefore, it is a pertinent area to be studied and explored.

\section{LITERATURE REVIEW AND CONCEPTUAL DEVELOPMENT}

The literature is replete with many studies on the impact of different drivers on poverty reduction. Flor (2001) explored the relationship between Technology and Poverty and concluded poor information was a source of poverty on the assumption that reach to information leads to way to resources as information causes opportunities and to opportunities that generate resources. Dollar and Kraay (2002) agreed that constant and speedy growth over a period resulted in fall of poverty ratio. Datt and Ravillion (2002) analyzed the link between economic growth and poverty at provincial level. Roy (2005) studied widespread disparity among the various states of India in terms of poverty and location. Greenberg (2005) found that ICT was a critical enabler and powerful tool for poverty alleviation and essential component for handling various issues related to poverty. Stern (2006) focused on the inter-linkages between global poverty and global warming. Ravallion, Chen, and Sangraula (2007) suggested that urban growth was the most important driver to bring greater national progress and favorable impact on rural poverty. 
Scholars identified need or necessity based entrepreneurship as a driver for poverty reduction, wherein poor impelled into self-employment due to dearth of opportunities at low level of economy (GEM, 2009). Van Sandt and Sud (2012) developed a collaborative model of profitable partnership among the government, social institutions, and business to alleviate poverty. The enhancing economic growth through economies of scale and increased productive can reduce poverty (Naim, 2013). Economist recognized entrepreneurship and new venture creation can significantly solve poverty issue across globe (Alvarez et al., 2015).

According to World Bank, Inclusive growth is prerequisite for speedy and sustained poverty reduction that encourage people, not only to participate and contribute but also enjoy the benefits of this growth, which is spread across the sectors (Ianchovichina and Lundstrom, 2009). Inclusive growth encompasses both pace and pattern of growth, which is indispensable for sustainable development as well as poverty reduction as reflected in Growth Report: Strategies for Sustained Growth and Inclusive Development (Commission on Growth and Development, 2008). Inclusiveness can be benchmarked against the achievement of quantifiable targets related to many socio-economic variables.

It is therefore pertinent to explore the impact of these socio-economic determinants on poverty reduction in India. Though there are many socio-economic indicators available to find out the impact on the Poverty Head Count Ratio, yet the present study has taken selective indicators such as; Human Development Index (HDI), Gini coefficient, Gross State Domestic Product (GSDP), Work Participation Rate (WPR) and Mahatma Gandhi National Rural Employment Guarantee Act (MGNERGA) expenditure. These indicators are key variables of inclusive and sustainable growth.

Thus, the present study tries to study the combined impact of these key socioeconomic indicators on the Poverty Head Count Ratio across the different states of India in the year 2009-10 and 2011-12. The study concludes that the HDI significantly affects the Poverty Head Count Ratio. Further, this study reviews that the government's inclusive initiatives in recent years, are also directed towards improvement of HDI, Therefore, the cause of recent decline in poverty ratio in India during the Modi reform era, needs to be explored. This study highlights the key inclusive initiatives of performance and supports these initiatives for poverty reduction.

\section{OBJECTIVES}

1. To study the impact of selective socio economic determinants on Poverty Headcount Ratio in the year 2009-10 and 2011-12 across Indian states.

2. To review and identify key government inclusive initiatives leading to poverty reduction in India from 2015 to 2018.

\section{RESEARCH DESIGN}

This study is based on secondary data. The data are collected from various sources: Census of India 2011; NSSO 66th Round; NHRD Data Sheet; India Human Development Report 2011; Consumer Expenditure surveys for NSS rounds 2009-10; Data-book Planning Commission.

The sample size of the study is 28 states of India. The data of 28 states of the year 2009-10 and 2011-12 have been considered on all the selective indicators, i.e., HDI, WPR, Gini-coefficient, GSDP, MGNERGA expenditure and Poverty Head Count Ratio. The data for HDI and Gini coefficient for the year 2011-12 are calculated on the basis of compound annual growth rate. The variation in the poverty headcount ratio, having the combined effect of independent socioeconomic variables, has been measured through the multiple regression model. The basic assumptions underlying the multiple linear regressions were tested for not being seriously violated such as normality, multi-collinearity, and homoscedasticity. SPSS is used to depict the results.

\section{DATA ANALYSIS}

To assess the combined impact of these selective socioeconomic indicators on the Poverty Head Count Ratio, i.e., dependent variable, multivariate analysis has been carried out. Thus, this section reports and interprets the results of multivariate analysis using multiple linear regression models. Before proceeding further, the basic assumptions underlying the multiple linear regressions were tested for not being seriously violated. The following subsections present results of these tests.

\section{Normality Test}

In the present study, consider the data of 28 states in India of the Year 2009-10 and 2011-12. Therefore, Shapiro-Wilk test is used to check the normality of all variables. 
Table 1: Tests of Normality (2009-10)

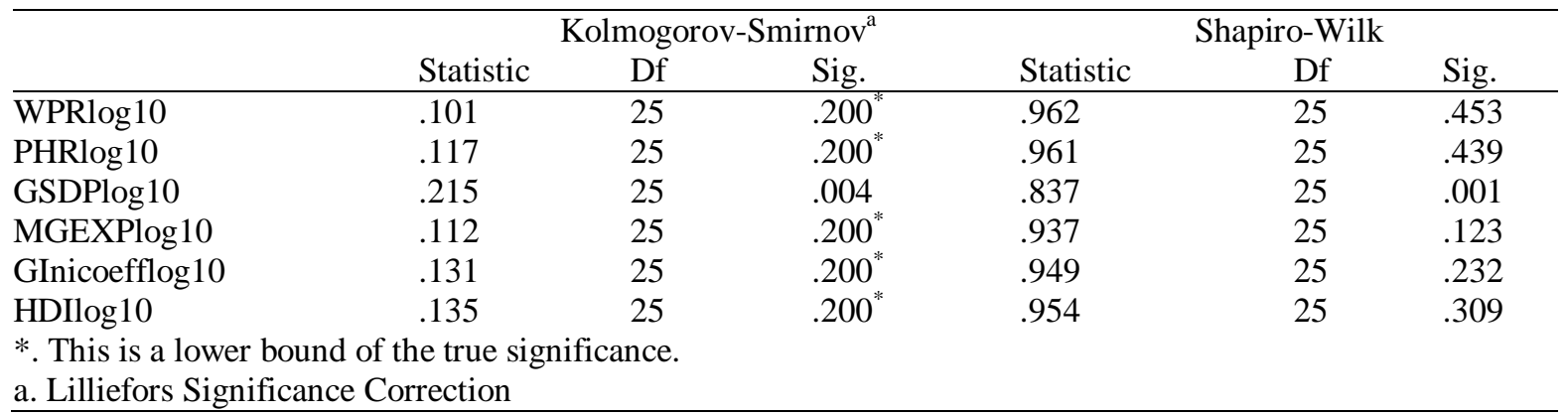

Table 1 depicts that one of the independent variable, i.e. GSDP is not found normally distributed and does not fulfill the assumption of normality as the P- value is .001 i.e. less than .05 in the year 2009-10. Therefore, this variable is not carried further for study in the year 2009-10.

Table 2: Tests of Normality (2011-12)

\begin{tabular}{lllllll}
\hline & \multicolumn{3}{c}{ Kolmogorov-Smirnov $^{\mathrm{a}}$} & \multicolumn{3}{c}{ Shapiro-Wilk } \\
& Statistic & Df & Sig. & Statistic & Df & Sig. \\
\hline L10WPR & .100 & 28 & $.200^{*}$ & .975 & 28 & .728 \\
L10PHR & .148 & 28 & .122 & .940 & 28 & .109 \\
L10GSDP & .077 & 28 & $.200^{*}$ & .976 & 28 & .737 \\
L10Ginicoeff & .117 & 28 & $.200^{*}$ & .970 & 28 & .571 \\
L10HDI & .107 & 28 & $.200^{*}$ & .968 & 28 & .539 \\
L10MGNERGA & .174 & 28 & .030 & .831 & 28 & .000 \\
*. This is a lower bound of the true significance. & & & & \\
\multicolumn{2}{l}{ a. Lilliefors Significance Correction }
\end{tabular}

Table 2 shows that one of the independent variable, i.e. MGNERGA expenditure is not found normally distributed and does not fulfill the assumption of normality as the P-value is .000 i.e. less than .05 in the year 2011-12. Therefore, this variable is not carried further for study in the year 2011-12.

\section{Multi-collinearity Diagnostics}

Multi-collinearity refers to the presence of highly inter-correlated independent variables in regression models.

Table 3: Collinearity Statistics

\begin{tabular}{lcc}
\hline \multirow{2}{*}{ Predictors } & \multicolumn{2}{c}{$2009-10$} \\
& Tolerance & VIF \\
\hline WPR & .687 & 1.455 \\
GiniCoeff & .883 & 1.132 \\
HDI & .636 & 1.571 \\
MGNERGA Exp. & .893 & 1.120 \\
\hline
\end{tabular}

Table 3 depicts that tolerance level and variance inflation factor for all the independent variables are under the permissible limit and free from multi-collinearity in the year 2009-10. Therefore, it can be concluded that the issue of multi-collinearity does not exist among the independent variables.

Table 4: Collinearity Statistics

\begin{tabular}{lll}
\hline \multirow{2}{*}{ Predictors } & \multicolumn{2}{c}{$2011-12$} \\
& Tolerance & VIF \\
\hline WPR & .807 & 1.239 \\
GSDP & .958 & 1.044 \\
GiniCoeff & .787 & 1.271 \\
HDI & .904 & 1.106 \\
\hline
\end{tabular}

Table 4 shows that all the independent variables which are considered in the year 2011-12, have VIF value less than 10 and tolerance value is more than 0.10 . Therefore, it can be concluded that the issue of multi-collinearity does not exist among the independent variables. 


\section{Homoscedasticity of Residuals}

Homoscedasticity means having a constant variance for all of the independent variables. A commonly used graphical method is to plot the residuals versus predictor values. The following figure presents the plot of the residuals against the predicted values individually for the years 2009-10 and 2011-12.

\section{Scatterplot}

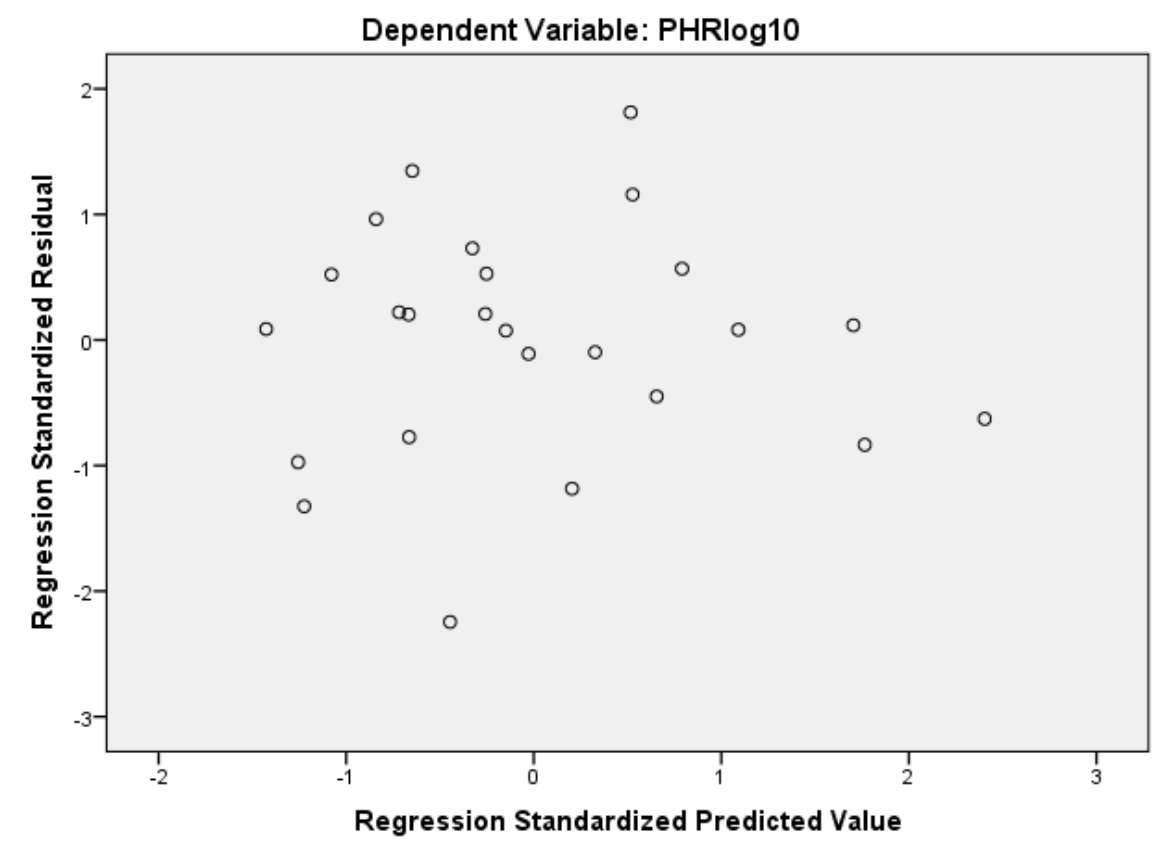

Figure 1: Year 2009-10

In the year 2009-10, Mahalanobis is found to be 10.659 .

Scatterplot

\section{Dependent Variable: L10PHR}

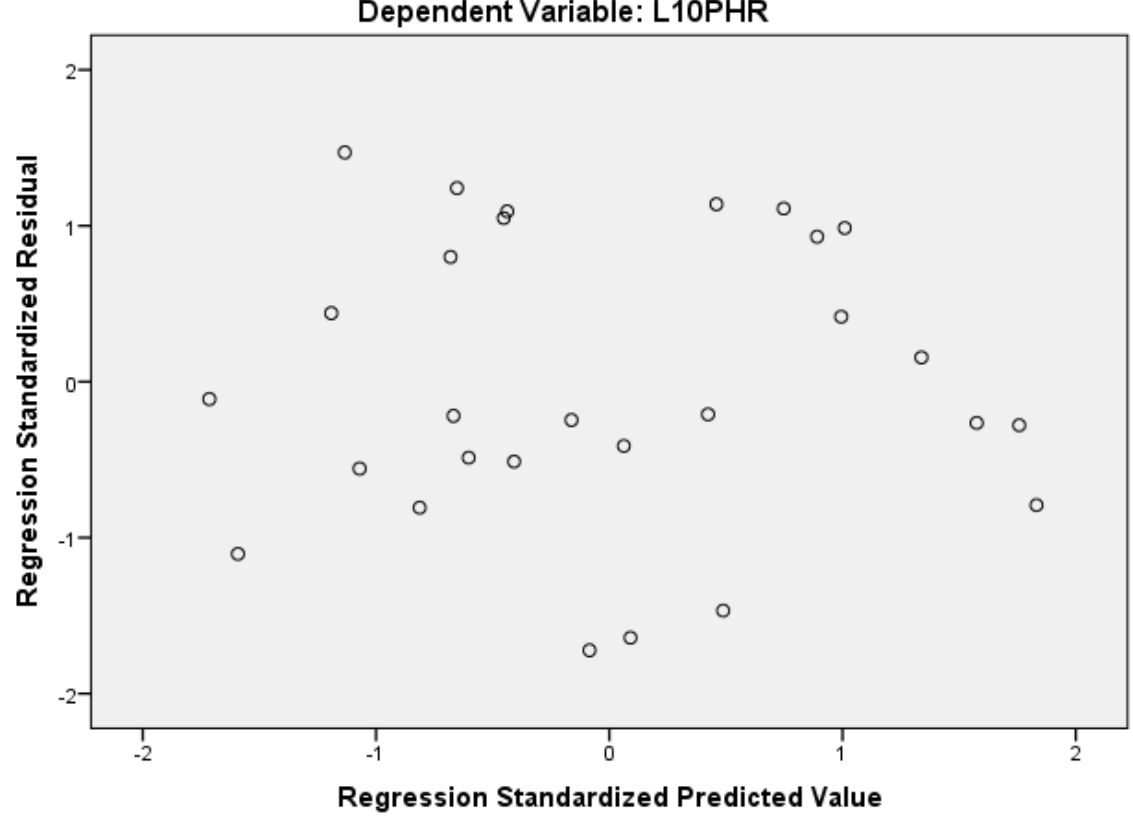

Figure 2: Year 2011-12

In the year 20011-12, Mahalanobis is found to be 9.990 .

\section{Multiple Linear Regression Analysis}

The regression equation is: 
$\mathrm{Y}=\alpha+\beta 1 \mathrm{X} 1+\beta 2 \mathrm{X} 2+\beta 3 \mathrm{X} 3+\beta 4 \mathrm{X} 4+\varepsilon$

Table 5: Multiple Linear Regression Results 2009-10

\begin{tabular}{lllll}
\hline Independent Variables & Co-efficients & Std. Error & t-statistics & Sig. \\
\hline (Constant) & 1.258 & 1.017 & 1.237 & .231 \\
WPRlog10 & .115 & .498 & .231 & .820 \\
MGNERGA Ex.Log10 & -.090 & .040 & -2.223 & .038 \\
Gini Coefficientlog10 & .016 & .343 & .047 & .963 \\
HDIlog10 & -.610 & .110 & -5.546 & .000 \\
Adjusted R2 =0.683 & & & & \\
R Square $=0.736$ & & & \\
F statistics = 13.944 & & & & \\
F Sig.(P-value)=0.000 & & & \\
$* *$ Means significant at $0.01(\mathrm{P} \leq 0.01)$ & & & \\
\hline
\end{tabular}

In order to test the statistical significance of each of the independent variables, whether the unstandardized (or standardized) coefficients are equal to 0 (zero) in the population, $\mathrm{p}<.05$, it is concluded from the "Sig." column in Table 5 that all independent variable coefficients are not statistically significantly except the HDI and MGNERGA Expenditure.

Table 6: Multiple Linear Regression Results 2011-12

\begin{tabular}{lllll}
\hline Independent Variables & Co-efficients & Std. Error & t-statistics & Sig. \\
\hline (Constant) & 1.053 & 1.017 & 1.035 & .321 \\
WPR & -.009 & .540 & -.183 & .857 \\
GSDP & -.037 & .324 & -.115 & .909 \\
Gini Coefficient & .071 & .421 & .168 & .868 \\
HDI & -.838 & .140 & -5.984 & .000 \\
Adjusted R2 =0.570 & & & & \\
R Square $=0.634$ & & & \\
F statistics $=9.948$ & & & & \\
F Sig.(P-value)=0.000 & & & \\
$* *$ Means significant at $0.01(\mathrm{P} \leq 0.01)$ & & & \\
\hline
\end{tabular}

Table 6 shows no significant coefficients of all independent variable except the HDI. Thus, it is concluded that in the year 2009-10, both HDI and MGNERGA expenditure significantly affected the Poverty Head count ratio, but in the year 2011-12, only HDI significantly affected the dependent variable.

Human Development Index is a composite index of three indicators: health, education, and real GDP per capita. Since 2015, the government of India has initiated many inclusive initiatives in the areas of education and health and for generating income to reduce poverty, resulting in its effectiveness in the Indian context.

\section{Government Incusive Initiatives and Poverty Reduction}

Today we live in knowledge economy. India started its technological revolution through the Digital India initiative launched by the government of India on 2 July 2015, which bring digitizing in all fields and make available resources faster to everyone. It will make possible actual democratic participation. The government of India launched major inclusive initiatives under digital India, majorly in the area of education, health, and employment generation, causing poverty reduction. Modi (2018) stated that India had been working towards building developed and inclusive economy by using technology and through poverty reduction for the last four years during his address in Stockholm University, Sweden.

GOI launched so many programs under e-kranti (an Initiative of digital India) for income generation and improving health and education. Under digital education GOI launched e-Basta (digital books for school), e-Education (schools are digitally connected through free wifi), NandGhars (digital tools as teaching aids), India Skills Online (Online training to enhance skills), and SWAYAM (MOOCs based, free education delivered in classrooms from class 9th to higher level, i.e., $\mathrm{PhD}$ ). SWAYAM is comprehensive and transformation project, which make available free access to education to everyone. This initiative is simultaneously creating job opportunities for its stakeholders. However, digital literacy is the biggest challenge on this path.

Access to quality health for everyone is one of the major focal areas under Digital India by enabling quick information flow, digital collaborations and providing economic and on time health services under e-health and e-hospital pillars. e- 
Hospital is a one-stop solution and connecting hospitals, doctors, and patients on the digital platform. However, there are challenges of setting legislation and formulating policies regarding electronic health, data, privacy, and security.

In order to achieve Universal Healthcare, the most exciting, the first of its kind program has been launched this year Ayushman Bharat. Ayushman Bharat comprises two pillars, i.e., Pradhan Mantri Rashtriya Swasthya Suraksha Mission (PMRSSM) and the Pradhan Mantri Health and Wellness Centers (HWC). PMRSSM is the largest publicly funded health protection scheme of the world.

Jan Dhan Yojana is a leading initiative towards financial inclusion by the Modi government, making easily accessible organized banking sector to masses in a true democratic way. In the last four years, every family was targeted to have bank account through Jan Dhan Yojana. A total of 31.52 crore Jan Dhan accounts were opened. Insurance coverage was increased through life and accident insurance, 19 crore people opted for Jan insurance. Direct Benefit Transfer was initiated for improving financial inclusion- in last 4 years about 431 different schemes included in DBT. An amount of 365996 crores of various schemes benefits were transferred directly in bank accounts of beneficiaries.

The 'Skill India' initiative is not just a vision, it is a committed action towards empowering India with skill sets which will determine a bright future for Indian industry and economy in the next 20-30 years. A number of result-driven initiatives have been launched to catalyze and propel transnational skill development. Key amongst these is the Pradhan Mantri Kaushal Vikas Yojna (PMKVY) under which a large section of the Indian youth is being mobilized to take up skill training in a bid to increase their employability. As of 31 March 2018, 23 lakh candidates have enrolled with over 17 lakhs successfully achieving training across sectors that fall under Short Term Training and Special Projects, Start Up India, and Mudra Yojna for encouraging entrepreneurship and increasing self-employment.

The aforementioned inclusive initiatives of the government of India in the area of education, health, and income generation has resulted in poverty reduction in India, as the country is no longer a home of the largest poor in the world as it was in 2016 and dropped to number three in the world. US think tank Brookings Institution published a report titled 'The start of a new poverty narrative' concluded that there was a significant decline in poverty headcount ratio in India in absolute term. Poor population climbed down from 125 million to 75 million in between 2016 to 2018 with further estimated to fall more 20 million by 2022 (Kharas et al., 2018).

\section{CONCLUSION}

It depicts the status of poverty in India and identifies HDI as the most important determinant affecting poverty in India. It underlines that the major inclusive initiatives through digital India during the Modi reform era have also been coincidentally directed towards the improvement of health and education and the generation of income, resulting in the reduction of poverty. Thus, right initiatives require the right direction for their effectiveness.

\section{LIMITATIONS AND STUDY FORWARD}

The study has limitations in terms of considering major inclusive determinants of poverty and the availability of data on these indicators. The study has a scope of comparative research studies among different developing countries on a similar line and a standard model of poverty reduction can be created for developing countries.

\section{REFERENCES}

Alvarez, S. A., Barney, J. B., \& Newman, A. M. B. (2015). The Poverty Problem and the Industrialization Solution. Asia Pacific Journal of Management, 32, 1-22.

Bruton,G. D., Ketchen, D. \& Ireland, D. (2013). Entrepreneurship as a solution to poverty. Journal of Business venturing, 28(6), 683-689.

Datt, G. \& Ravallion, M. (2002). Is India's Economic Growth Leaving the Poor Behind? Journal of Economic Perspectives, 16 (3), $89-108$.

Dollar, D., \& Kraay, A. (2002). Spreading the wealth. Foreign Affairs, 81(1), 120-133.

Naim, M. (2013). The End of Power: From Boardrooms to Battlefields and Churches to States, Why Being in Charge isn't What It Used to be. New York: Basic Books.

Narayan, D., Patel, R., Schafft, K., Rademacher, A., \& Koch-Schulte, S. (2000). Voices of the poor: can anyone hear us ? (English). New York : Oxford University Press.

Ravallion, M., S. Chen, P. Sangraula. (2007). New Evidence on the Urbanization of Global Poverty. Population and Development Review, 33 (4), 667-702.

Roy, K.C. (2005). Historical Pattern of India's Economic Growth: Salient Features. International Journal of Social Economics, 32(11), 951-967. 
Sachs, J. (2005). The End of the Poverty. The Penguin Press, New York, NY.

Sen, A. (1976). Poverty: An Ordinal Approach to Measurement, Econometrica, 46, 437-446.

Sen, A. (1999). Development as freedom. New York: Anchor Books.

Shepherd, A. (2007). Chronic Poverty: Some Policy Implications. Development, 50 (2), 48-55.

Smith, A. (1776). Wealth of Nations (2007 ed). Cosimo, Inc. - ISBN: 9781602069404

Srinivasan, T.N. (2013). Planning, Poverty and Political Economy of Reforms: A Tribute to Suresh Tendulkar. Indian Economic Review, 48 (1), 1-32.

VanSandt C. V. \& Sud M. (2012). Poverty Alleviation through Partnerships: A Road Less Travelled for Business, Governments, and Entrepreneurs. J Bus Ethics, 110, 321-332.

\section{FURTHER READINGS}

Choudhury, G. (2015). Demystifying India's poverty line: Here's everything you need to know. Hindustantimes, Retrieved from http://www.hindustantimes.com/business/demystifying-india-s-poverty-line-here-s-everything-youneed-to-know/story-43vy1sQ7LrCZuezTakDnkM.html. Accessed Aug. 9, 2018

Duraippah, A. (1996). Poverty and environmental protection: A literature review and analysis. (Creed Working Paper Series No. 8), International Institute for Environment and Development, London, http://www.premonline.org/archive/17/doc/creed08e.pdf Accessed July 11, 2018

Economic Survey 2014-15. Union Budget and Economic Survey. Ministry of Finance, Government of India, New Delhi.

Flor, A.G. (2001). ICT and poverty: the indisputable link. Paper presented for Third Asia Development Forum on 'Regional Economic Cooperation in Asia and the Pacific', Bangkok, Retrieved fromwww.ethnosproject.org/wpcontent/uploads/ICT-and-poverty.pdfAccessed Aug. 8, 2018.

Global Entrepreneurship Monitor (2009). http://www.gem consortium.org/. Accessed 10 Jan. 2018.

Greenberg, A. (2005). ICT's for Poverty Alleviation: Basic Tools and Enabling Sector. ICT For Development Secretarait, Sida, https://www.sida.se/contentassets/e2425616ca0542e0a55270d5087e0c3a/icts-for-povertyalleviation_1080.pdf Accessed Aug. 9, 2018

Ianchovichina, E. \& Lundstrom, S. (2009). Inclusive Growth Analytics: Framework and Application. (Policy Research Working paper -4851). The World Bank, Economic Policy and Debt Department. Retrieved from https://openknowledge.worldbank.org/bitstream/handle/10986/4047/WPS4851.pdf;sequence=1 Accessed May 23, 2018

Kharas H., Hamel, K. \& Hofer, M. (2018). The Start of a New Poverty Narrative. Future Development blog of BROOKINGS. Retrieved from https://www.brookings.edu/blog/future-development/2018/06/19/the-start-of-a-newpoverty-narrative/ Accessed Aug, 8, 2018

Nalunkuuma, J. (2006) Microfinance and Outreach: A case study of Soroti Catholic Diocese. Integrated Development Organisation, The Hague: ISS Accessed Sept.15, 2018

Odusola (2001). Conceptual issues in poverty and poverty measurement. Paper presented at NCEMA Workshop on poverty alleviation policies and strategies, 15th - 26th,October. Accessed May 7, 2018

Ogwumike (2001). Profile and dimension of poverty in Nigeria. Paper presented at NCEMA workshop on poverty reduction, Development policy centre, Ibadan, 3rd-21st August. Accessed May 6, 2018

UNDP (2018). 271 million fewer in India. Retrieved from http://www.in.undp.org/content/india/en/home/sustainabledevelopment/successstories/MultiDimesnionalPovertyInd ex.html Accessed on Oct. 10, 2018.

World Bank (2008). New Data Show 1.4 billion Live on Less than $\$ 1.25$ a day, But Progress against Poverty Remains Strong. http://web.worldbank.org/archive/website01291/WEB/0__C-248.HTM. Accessed Sept. 22, 2018 